Article

\title{
The Sustainable Development of the Economic-Energy-Environment (3E) System under the Carbon Trading (CT) Mechanism: A Chinese Case
}

\author{
Xingang Zhao ${ }^{1,2}$, Yuzhuo Zhang ${ }^{1,2, *}$ (D) , Ji Liang ${ }^{1}$, Yanbin $\mathrm{Li}^{1,2}$, Rongda Jia ${ }^{3}$ and Ling Wang ${ }^{4}$ \\ 1 School of Economics and Management, North China Electric Power University, Beijing 102206, China; \\ 1162106029@ncepu.edu.cn (X.Z.); 1162106002@ncepu.edu.cn (J.L.); 1152206070@ncepu.edu.cn (Y.L.) \\ 2 Beijing Key Laboratory of New Energy and Low-Carbon Development, Beijing 102206, China \\ 3 State Grid Energy Conservation Service Co., Ltd., Beijing 100052, China; 1162206007@ncepu.edu.cn \\ 4 State Grid Liaoning Electric Power Co., Ltd., Benxi Power Supply Company, Benxi 117020, China; \\ 1162206008@ncepu.edu.cn \\ * Correspondence: hdzyz1102@126.com
}

Received: 11 December 2017; Accepted: 2 January 2018; Published: 3 January 2018

\begin{abstract}
The implementation of the carbon trading (CT) mechanism is important for the transformation of China's renewable energy industry, thereby affecting the structure of energy, economy, and the environment, and determining the sustainable development of China's economic-energyenvironment (3E) system in the future. This paper constructs a 3E system simulation model under the CT mechanism based on the theory of system dynamics and taking the Beijing-Tianjin-Hebei region as an example. We study the internal operation mechanism of the carbon emissions trading system and its impact on $3 \mathrm{E}$ by combing the related mechanisms of the $\mathrm{CT}$ market, $\mathrm{CO}_{2}$ emissions, energy consumption, and gross domestic product (GDP), thereby helping to provide references for policy-making institutions. The results show that the implementation of $\mathrm{CT}$ can effectively reduce energy consumption growth and carbon emissions in the Beijing-Tianjin-Hebei region, and the negative impact of CT implementation on GDP is significantly lower than its positive impact on reducing carbon emissions and energy consumption. Thus, the CT mechanism is conducive to the sustainable development of the Beijing-Tianjin-Hebei region's 3E system. In addition, reducing the total amount of quota, reducing free quota, and increasing CT price can effectively promote carbon emission reduction, thus promoting the sustainable development of the $3 \mathrm{E}$ system.
\end{abstract}

Keywords: sustainable development; economic-energy-environment (3E) system; carbon trading (CT); system dynamics (SD); China

\section{Introduction}

In recent years, the problem of the greenhouse effect and climate warming has had a great influence on production and the life of human beings with the rapid development of the economy. In this context, China is actively undertaking the task of carbon emission reduction and the implementation of a low-carbon economy. Among the energy policies, carbon trading (CT) has become an important tool for effectively reducing carbon emissions. The CT mechanism was first mentioned in the Kyoto protocol. Its meaning is to trade carbon dioxide emission rights as a commodity, thus forming a carbon emissions trading market, that is, a CT market. Compared with the carbon tax policy imposed by the state, the CT mechanism can be a more flexible and effective use of market mechanisms to achieve carbon reduction targets. In October 2011, China formally designated seven provinces and cities for the first batch of carbon emission trading pilot projects, which are Beijing, Tianjin, Chongqing, Shanghai, Hubei, Guangdong, and Shenzhen, and the Chinese government will set up 
a nationwide CT market by 2018 [1]. The establishment of the CT market will inevitably affect the economy, energy, and the environment of China, and then affect the coordinated development of the economic-energy-environment (3E) system.

The study of CT has attracted much attention of scholars. Chappin and Dijkema [2] introduced the multi-agent model to analyze the impact of CT mechanism on the production decision of the power enterprises in the oligopoly market. Mo et al. [3] used the multivariate market model to study the impact of different CT mechanisms and price changes on European Union (EU) power companies. Tang et al. [4] built a multi-agent model to explore the impact of the CT mechanism on China's carbon emissions and economic development. Meanwhile, the benchmarking rule and the grandfather rule in the initial allocation mode of carbon quotas have been compared. Cong and Wei [5] used the agent model to study the potential impact of the CT mechanism on China's power industry. Zhao et al. [6] analyzed the market efficiency of China's CT market for price, trading volume, market liquidity, and information transparency, and they found that the market efficiency is not satisfactory. Wang and Wang [7] used a series of variance ratio tests and ADF tests to investigate whether China's carbon trading market is efficient based on the data from the pilot trading market and, the results show that part of the pilot trading market achieved weak efficiency. Zhao et al. [8] developed the unit root test and the run test to analyze the carbon emission market of four representative cities in China based on the effective market theory and fair game model. Liu et al. [9] took Beijing, China as an example to study the CT market mechanism and its impact on economy and the environment. Kanamura [10] examined the role of carbon swap trading and energy prices in volatilities and price correlations between the EU and Kyoto Protocol emissions trading schemes. Rannou and Barneto [11] analyzed the relationship between the European carbon market efficiency and its volatility/liquidity. Balietti [12] believes that the trading activity-volatility link is relevant for evaluating the efficiency of the EU ETS. Yin and Mei [13] analyzed the impact mechanism of the CT system on industries by constructing a theoretical framework. Zhou [14] developed CGE model to simulate the economic impacts and co-benefits of different CT schemes under alternative employment conditions. Zhang et al. [15] used a computable general equilibrium model to analyze the impact of the CT mechanism on industrial structure, energy structure, and the international trade of China, and clarified the role of China in the context of the global emission trading system. Koljonen and Savolainen [16] discussed the impact of the EU emissions trading studied using a stochastic electricity price model for the Nordic electricity markets and the TIMES energy systems model to describe the development of the Finnish energy economy. Schleich et al. [17] studied the incentive effect of the CT system on energy efficiency, and put forward that a high carbon price will have a strong incentive for energy efficiency at the demand level.

The existing researches mainly analyze and demonstrate the CT market mechanism and its impact on energy, environment, and economic development, respectively. However, $3 \mathrm{E}$ is a coordinated development system, and there are few literature studies on the impact of the CT market mechanism on the entire 3E system. The development of the economy provides sources of labor in production and a living for the energy subsystem, and promotes the development of the environmental protection industry for the environment subsystem. Energy is the foundation of equipment development and technical support for the economic subsystem, and it produces carbon emissions for the environment subsystem. The environment provides space support for the economic subsystem and resources for the energy subsystem. Thus, our goal is to fill this gap. Since the $3 \mathrm{E}$ system is a typical complex system, this paper uses the system dynamics (SD) model with high-order, nonlinear and multiple feedback to build a sustainable development model of a $3 \mathrm{E}$ system under the $\mathrm{CT}$ mechanism. The model includes economic, energy, environmental and CT modules, and clearly reveals the interaction between the various modules to realize the simulation research of $\mathrm{CT}$ on the $3 \mathrm{E}$ system. In addition, this paper explores the impact of different CT policy designs on the economy and environment taking Beijing-Tianjin-Hebei region as an example, and examines the effectiveness and practicability of the SD model, thus providing effective policy recommendations for relevant government departments. 


\section{Methodology}

According to the foregoing, we can see that many scholars have constructed a lot of models to study the CT market mechanism and its impact on energy, environment, and economic development, respectively, such as the multi-agent model, variance ratio tests, unit root test, and the CGE model. However, the dynamics of development of the 3E under CT are complex. Most of the existing models examine the static impact of the factors on 3E's development, and few examples visually indicate the complex relationship between various important factors and the long-term $3 \mathrm{E}$ development.

$\mathrm{SD}$ is a systems modeling and dynamic simulation methodology for the analysis of dynamic complexities in socio-economic and biophysical systems with long-term, cyclical, and low-precision requirements [18]. Through the complex relationship between the various elements of the system, SD establishes a relatively effective model, which can achieve the predetermined goal and meet the predetermined requirements. Based on the principle of system thinking and feedback control theory, SD helps in understanding the time-varying behavior of complex systems [19]. The 3E system under CT mechanism is a typical complex system, which involves many factors that are complex and changeable, such as economy, environment, energy, and CT policy. These factors affect and restrict each other and determine the development trend of 3E. The 3E system under CT mechanism involves multivariable, high order, and nonlinear, dynamic feedback complex systems, with obvious SD characteristics. Although other types of quantitative modeling can be used for impact analysis, the SD model, which has the advantage of solving dynamic problems, can better simulate the process of development of 3E [20].

\subsection{Causal Loop Diagrams (CLD) Analysis}

The SD model built in our study contains four modules, which are economy, energy, environment, and carbon trading, including the key variables of $\mathrm{CO}_{2}$ emissions, gross domestic product (GDP), energy consumption, environmental investment, and CT policy. Among them, economic development stimulates energy consumption, while the energy consumption also produces a large amount of $\mathrm{CO}_{2}$. The increase of carbon emissions, on the one hand, needs to be treated by increasing environmental aspects. On the other hand, it increases the costs of emission reduction in the CT market, which has a negative impact on the growth of GDP. In addition, economic development will promote investment in fixed assets, and the increase of investment in fixed assets will promote economic growth in turn. This study uses causal loop diagrams (CLD) to represent the relations of the SD model, as shown in Figure 1, in which the arrow indicates the relationship between factors and the direction of influence, and the positive and negative sign represents the positive or negative correlation, respectively [21]. The theoretical framework is analyzed as follows.

\subsubsection{E Module}

(1) The core factors of the 3E system: The economic subsystem is composed of economic elements that are interconnected and have a causal relationship between each other, where, GDP is an important indicator to measure the overall economic situation of a country or region [21]. GDP growth will directly enhance energy investment, thereby promoting the development of the energy industry, eventually leading to an increase in energy consumption. The development of industry and the growth of energy consumption further aggravate $\mathrm{CO}_{2}$ emissions, which is the main cause of environmental pollution and greenhouse effect. Therefore, we set the core factors of the economic subsystem, energy subsystem, and environmental subsystem as GDP, energy consumption, and $\mathrm{CO}_{2}$ emissions, respectively.

(2) The feedback path of the economic subsystem: GDP $\rightarrow$ fixed assets investment $\rightarrow$ GDP growth $\rightarrow$ GDP, and GDP $\rightarrow$ industrial profits $\rightarrow$ GDP growth $\rightarrow$ GDP. The development of the economy has a positive effect on fixed assets investment, while the increase in fixed assets investment will in turn promote economic growth, and ultimately increase GDP. Similarly, economic development 
can promote the growth of enterprise outputs, and produce certain positive effects on industrial profits. The increase of profits will promote economic growth, and correspondingly, eventually promote the growth of GDP.

(3) The feedback path of the energy subsystem [18]: GDP $\rightarrow$ energy investment $\rightarrow$ energy supply $\rightarrow$ energy gap $\rightarrow$ energy policies $\rightarrow$ energy intensity $\rightarrow$ energy consumption, and GDP $\rightarrow$ energy consumption. The GDP growth will directly increase energy investment, and the supply and demand of energy will also increase, which lead to energy shortage. With the expansion of the energy gap, energy policies will be strengthened to reduce energy intensity, thereby reducing energy demand, and thus narrowing the energy gap.

(4) The feedback path of the environment subsystem: GDP $\rightarrow$ energy consumption $\rightarrow \mathrm{CO}_{2}$ emissions, and GDP $\rightarrow$ environmental investment $\rightarrow \mathrm{CO}_{2}$ emissions. On the one hand, economic growth promotes the energy industry's development, while the development of the energy industry generates a large amount of $\mathrm{CO}_{2}$. On the other hand, the increase of GDP will increase the government's investment in environmental governance, and thus reduce carbon emissions.

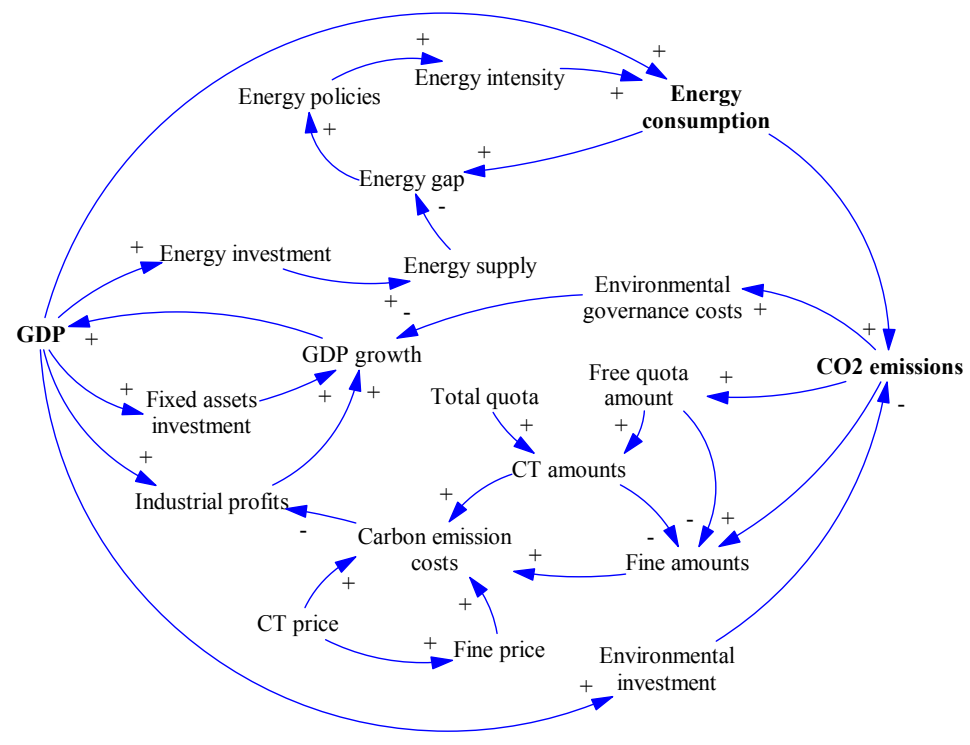

Figure 1. The theoretical framing of the system dynamics (SD) model of the economic-energyenvironment (3E) system under the carbon trading (CT) mechanism. Source: Authors.

\subsubsection{CT Module}

(1) CT market: In the CT market, the government sets a certain amount of total carbon emissions, that is, the total quotas, and sets the maximum amount of carbon emissions for each carbon-emitting enterprise, that is, free quotas. In order not to exceed the maximum carbon emissions, carbon emitters can purchase carbon indicators from other enterprises that do not fulfill their carbon emission targets at a certain price, to compensate for their excessive carbon emissions, thus forming the CT market for free transactions between enterprises. Enterprises need to be punished if they exceed the limit of carbon emissions. Both of the costs of purchasing carbon emissions and the fines they pay belong to the enterprises' carbon emission costs.

(2) The feedback path of the impact of the CT market on the 3E system: $\mathrm{CO}_{2}$ emissions $\rightarrow$ environmental governance cost $\rightarrow \mathrm{GDP}$ growth $\rightarrow \mathrm{GDP}$, and $\mathrm{CO}_{2}$ emissions $\rightarrow$ fine amounts $\rightarrow$ carbon emission costs $\rightarrow$ industrial profits $\rightarrow$ GDP growth $\rightarrow$ GDP. On the one hand, the increase of carbon emissions causes the government to invest more in harnessing the environment, and the increase of environmental governance costs will inevitably have some negative effects on economic development in the short term. On the other hand, when the total quota is fixed, for the larger carbon emissions, more penalties will be for the excessive emission enterprises, 
thus increasing the carbon emission costs. Correspondingly, the increase of carbon emission costs will increase the production costs, and have a negative effect on industrial profits, while the decrease of profits will restrain GDP growth [22].

\subsection{Model Design}

In order to ensure the rationality of the modeling, we need to make a hypothesis. The government's guidance and supervision directly determine the effectiveness of the implementation of the CT mechanism. Therefore, this paper assumes that the government can effectively implement the CT policy to ensure the 3E system's development.

Based on the analysis of the theoretical framing of the SD model of the 3E system under the CT mechanism, we believe that there is a complex nonlinear relationship between energy, economics, and environment under CT. A flow graph of the 3E system under CT using Vensim was established, as shown in Figure 2. The stock and flow diagram (SFD) is a good tool for modeling the cause and effect relationships between various components of the SD model [20]. The model design and main formulas are shown as follows.

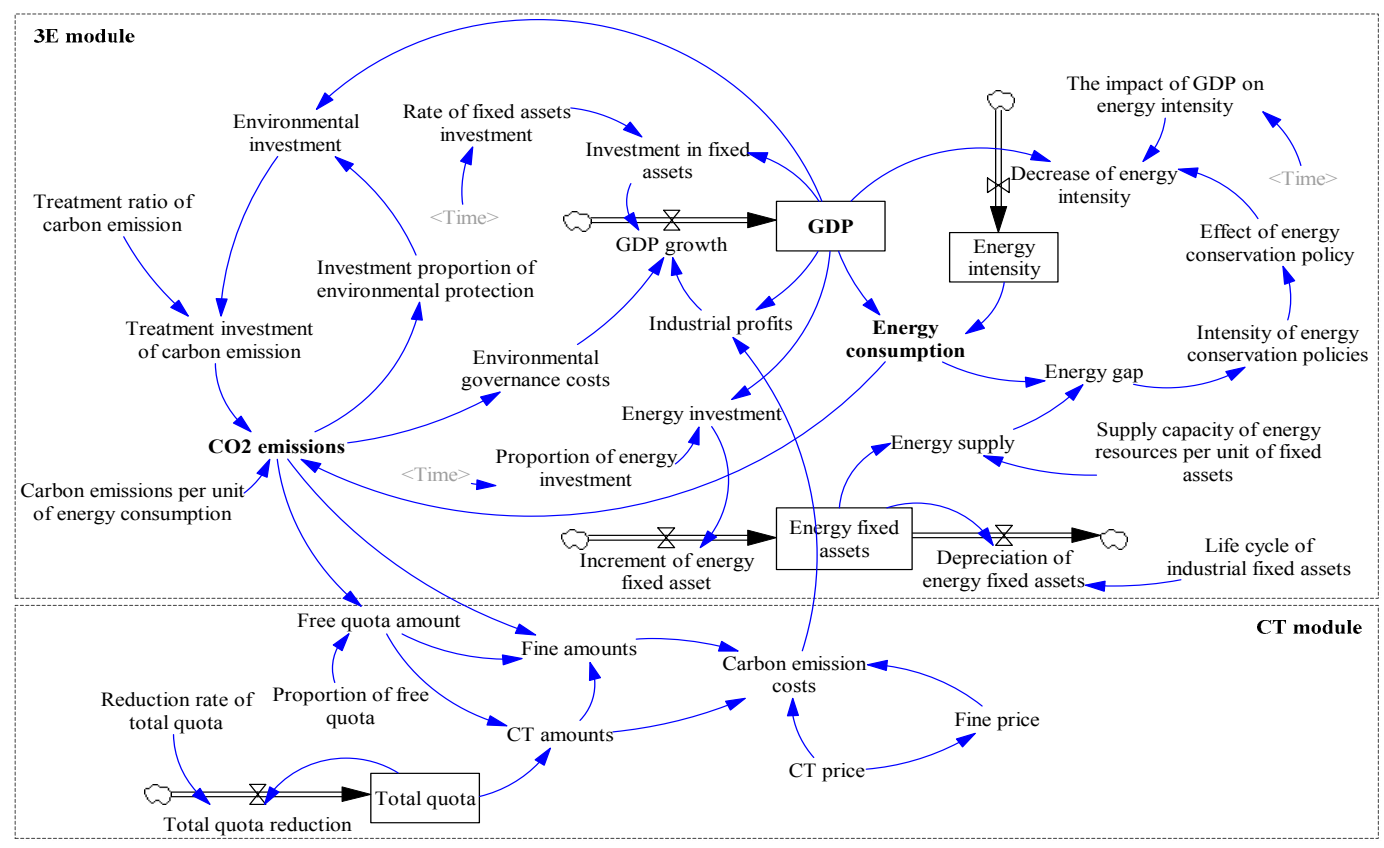

Figure 2. The stock and flow diagram (SFD) of the 3E system under CT. Source: Authors.

There are about forty control functions in this SFD to represent the quantitative relationship between parameters. In the case of limited text, the main formulas and important functional relationships in the flow chart are listed as follows. Appendix A gives the expression of the rest of the basic formulas in the model.

$$
G D P_{g}=\alpha \times I P+\beta \times I_{f}-\gamma \times E G C
$$

where, $G D P_{g}$ is GDP growth, IP is industrial profits, $I_{f}$ is investment in fixed assets, EGC is environmental governance costs, $\alpha, \beta$, and $\gamma$ are economic parameters. The greater the industrial profits and fixed assets investment, the higher the GDP growth. In contrast, the greater the environmental governance costs, the lower the GDP growth.

$$
E C=E I \times G D P
$$




$$
\begin{gathered}
I E P=E G \times \varepsilon \\
E E P=I E P \times \theta \\
D E I=E E P-G D P \times I E I \times \delta \\
E I=\int(-D E I)+E I_{0}
\end{gathered}
$$

where, $E C$ is energy consumption, $E I$ is energy intensity, IEP is intensity of energy conservation policies, $E G$ is energy gap, $E E P$ is effect of energy conservation policy, $D E I$ is decrease of energy intensity, $I E I$ is the impact of GDP on energy intensity, $E I_{0}$ is the initial value of energy intensity, $\varepsilon, \theta$, and $\delta$ are economic parameters.

There is an energy gap when the energy consumption is higher than the energy supply, and it is adjusted by energy policies. The greater the intensity of energy conservation policy, the better the effects of energy conservation policy, which produces a decline in energy intensity, and ultimately reduces the energy gap, thereby adjusting the supply and demand of energy [23]. Energy intensity is the energy consumption per unit of GDP, as shown in Formula (2). The intensity of the energy conservation policy is related to the energy gap, and the greater the energy gap, the greater the intensity of the energy conservation policy, as shown in Formula (3). Similarly, the greater the intensity of the energy conservation policies, the greater the effects of the energy conservation policies, as shown in Formula (4). The changes in energy intensity are related to the effect of energy conservation policies and the impact of GDP on energy intensity. If energy saving is better than the impact of GDP on energy intensity, energy intensity will decline, and vice versa, as shown in Formula (5). Since the decrease of energy intensity in Formula (5) is only a value without showing direction, the expression for energy intensity is shown as Formula (6).

$$
\mathrm{CO}_{2}=E C \times E_{\mathcal{C}}-\mathrm{TI}_{\mathcal{C}} \times \varphi
$$

where, $\mathrm{CO}_{2}$ is $\mathrm{CO}_{2}$ emissions, $E_{c}$ is carbon emissions per unit of energy consumption, $T I_{\mathcal{c}}$ is treatment investment of carbon emission, $\varphi$ is the economic parameter. $\mathrm{CO}_{2}$ includes carbon emissions from energy production and treatment, as shown in Formula (7). Where, $\varphi$ is the impact index of treatment investment on carbon emissions.

$$
\begin{gathered}
F A=C O_{2}-F Q A-C T \\
C_{c}=F A \times p_{f}+C T \times p_{C T} \\
p_{f}=\lambda \times p_{C T}
\end{gathered}
$$

where, $F A$ is fine amounts, $F Q A$ is free quota amount, $C T$ is $C T$ amounts, $C_{c}$ is carbon emission costs, $p_{f}$ is fine price, $p_{C T}$ is CT price, $\lambda$ is economic parameter. The enterprises need to be punished if they run out of free quotas and still exceed carbon limits after CT transactions. The fine amounts are the difference between actual carbon emissions and free quotas and CT transactions, as shown in Formula (8). The carbon emission costs are the sum of the fine and CT transaction costs, as shown in Formula (9). According to Ref. [24], the fine price is a certain proportion of the CT price under the control of the government. Therefore, the fine price is shown as Formula (10).

\subsection{Validation of Dynamic Models}

The SD model is a simulation of the real system. Model validation testing is to test whether the model has reached the goal of modeling and effectively reflected the reality. SD has established a variety of specific tests to detect defects and improve models, mainly including boundary adequacy, structure verification, dimensional consistency, an extreme condition test, and a structurally oriented behavior test. 


\subsubsection{Boundary Adequacy}

The model boundary test is to check whether the important concepts and variables in the system are endogenous variables, and whether the feedback loop is sufficient to describe the current problems. It can more clearly reflect the key issues studied in this paper, rather than focusing on those secondary research objects. Figure 3 summarizes the major endogenous and exogenous variables in the models.

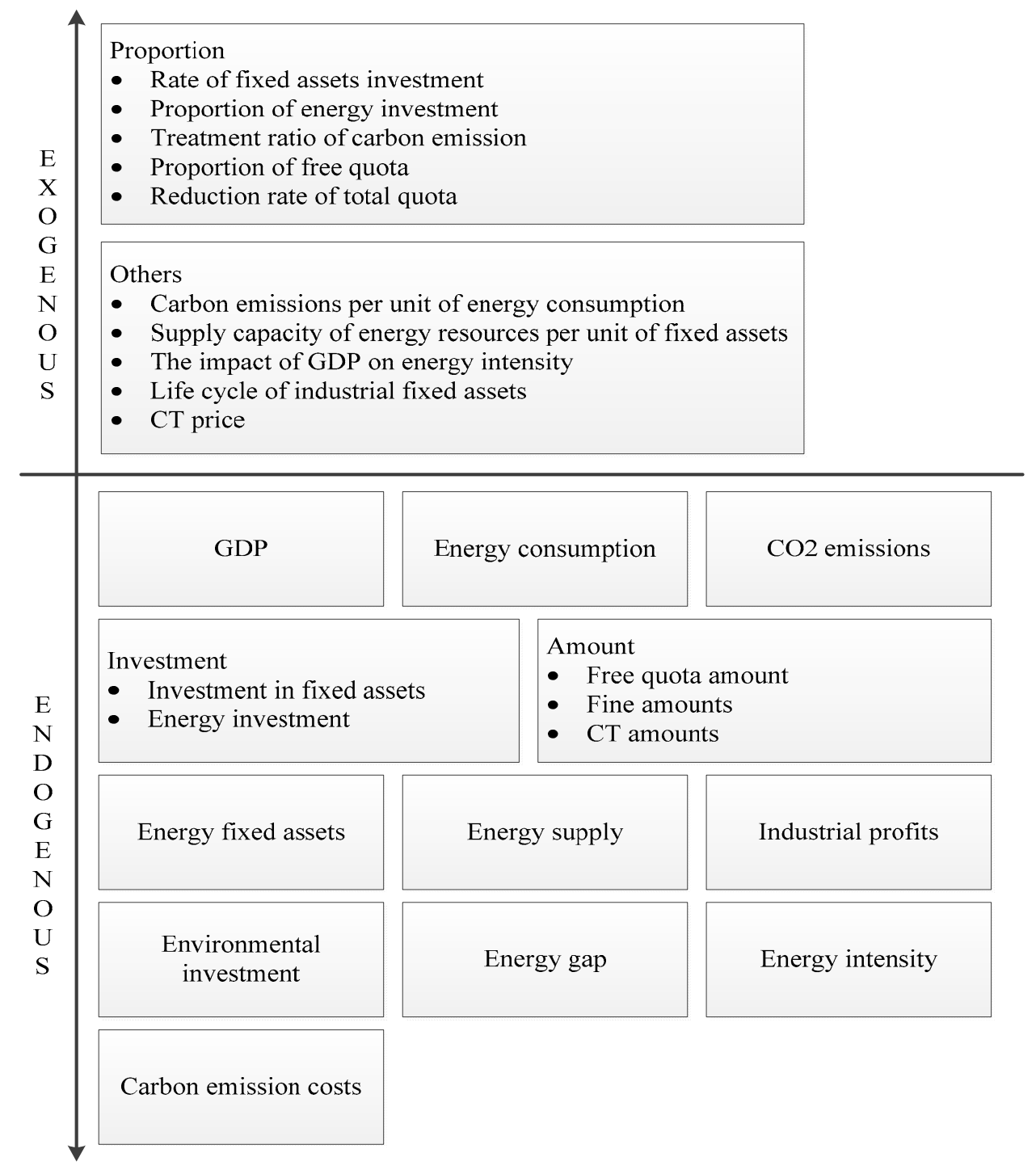

Figure 3. Summary of the model's boundary. Source: Authors.

\subsubsection{Structure Verification}

The structure validation of the model is tested mainly through the sub-models/structure of the existing models, shown in Table 1 . The structure test can guarantee the correctness and practicability of the model establishment. 
Table 1. The model's structures adopted from existing work.

\begin{tabular}{cc}
\hline Structures/Concepts & Remarks \\
\hline Economic and environment subsystems $[18,21]$ & Structural formulation was adopted \\
Energy subsystem $[23,25]$ & Structural formulation was adopted \\
Carbon trading $(\mathrm{CT})$ market $[6,22]$ & Causal structure was adopted \\
\hline
\end{tabular}

\subsubsection{Dimensional Consistency}

The dimensional consistency test requires that the parameters in the model must have the correct unit, so that the parameter has a definite meaning, and the units of all equations must be consistent. We used the "Units Check" function in Vensim software to test the model established in this paper. The results show that the units in the model are consistent.

\subsubsection{Extreme Condition Test}

The extreme conditions test is mainly used to test whether the equations in the model are stable and reliable, and whether the changes of real systems or the wishes of decision-makers can be reflected in any extreme cases. We set, (i) proportion of free quota is 0; and (ii) CT price and fine price are 0 as several extreme conditions. The simulation results show that; (i) when there is no free quota, the enterprises need to be punished for all carbon emissions, which will lead to a gradual reduction in industrial profits, so that the GDP, energy consumption and $\mathrm{CO}_{2}$ emissions gradually reduce to 0 ; (ii) when the enterprises do not need CT transactions and need not to be punished, they do not have to pay emission reduction costs, making the industrial profits grow by a large scale, and GDP, energy consumption, and $\mathrm{CO}_{2}$ emissions increase faster and faster. The extreme condition test shows that the model has good stability.

\subsubsection{Structurally Oriented Behavior Test}

In this test, official dataset from 2006 to 2015 and the results of the model can be compared to test the robustness of the model. We use a reality check to achieve the validation and verification of our model. The results are shown in Table 2. It is obvious that the MAPEs (mean absolute percentage errors) are all limited to a relative small interval $(0-3 \%)$. The relative error between the simulation value and the actual value is small, indicating that the model reflects the development trend of the Chinese 3E system well. 
Table 2. Model reality check.

\begin{tabular}{|c|c|c|c|c|c|c|c|c|c|c|c|c|}
\hline & 2006 & 2007 & 2008 & 2009 & 2010 & 2011 & 2012 & 2013 & 2014 & 2015 & $\begin{array}{c}\text { MAPE (Mean Absolute } \\
\text { Percentage Error) }\end{array}$ & $\begin{array}{l}\text { Data } \\
\text { Source }\end{array}$ \\
\hline GDP (108 Yuan) & 24,048 & 28,706 & 33,845 & 36,910 & 43,732 & 52,074 & 57,348 & 62,472 & 66,474 & 69,359 & 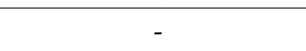 & [26] \\
\hline simulation results & 24,267 & 29,372 & 34,428 & 37,348 & 44,025 & 52,683 & 57,889 & 62,699 & 66,937 & 69,662 & $1.04 \%$ & SD model \\
\hline Energy consumption ( $10^{4}$ tons of standard coal) & 31,968 & 34,583 & 35,811 & 37,641 & 41,060 & 43,839 & 45,355 & 46,522 & 48,296 & 50,337 & - & [26] \\
\hline simulation results & 32,473 & 35,129 & 36,307 & 38,022 & 41,839 & 44,279 & 46,075 & 47,013 & 49,060 & 51,127 & $1.42 \%$ & SD model \\
\hline $\mathrm{CO}_{2}$ emissions ( $10^{4}$ Tons) & 48,884 & 51,912 & 54,668 & 56,985 & 62,501 & 68,821 & 73,086 & 74,509 & 78,200 & 81,968 & - & [26] \\
\hline simulation results & 49,916 & 53,116 & 55,610 & 58,231 & 64,170 & 70,314 & 74,506 & 76,270 & 79,527 & 83,965 & $2.16 \%$ & SD model \\
\hline
\end{tabular}




\section{Case Study}

As the national capital economic circle, the collaborative development of Beijing-Tianjin-Hebei region has attracted extensive attention from academia, politicians and the public [27]. The BeijingTianjin-Hebei region is the most economically developed region in northern China, and is also the region with the fastest economic growth and strongest comprehensive competitiveness in China [28]. In 2016, the GDP of Beijing-Tianjin-Hebei region was 7.46 trillion yuan, accounting for $10.02 \%$ of the national GDP. However, with the gradual expansion of the economy in the Beijing-Tianjin-Hebei region, the demand for energy is also gradually increasing, which has directly led to the rapid increase of carbon emissions. The total amount of energy consumption is 540 million tons of standard coal, accounting for about $12.4 \%$ of the national energy consumption, and the total amount of carbon emissions accounts for about $12 \%$ of the national carbon emissions [29]. In 2016, seven of the ten cities with the worst air quality in China were in the Beijing-Tianjin-Hebei region [30]. In response to the above problems, the Chinese government attaches great importance to the coordinated and sustainable development of energy, economy, and environment in the Beijing-Tianjin-Hebei region by implementing energy policies such as CT. Therefore, this study uses SD models to study the sustainable development pattern of the $3 \mathrm{E}$ system under $\mathrm{CT}$ in the future development of the Beijing-Tianjin-Hebei region.

\subsection{Data}

In order to show the dynamic effects of the $3 \mathrm{E}$ system development well, SD requires that the simulation step should be as small as possible. Therefore, we assume that the step length is one month. In general, the implementation period of national energy policy ranges from 5-10 years [31], thus, to study the impact of policy on the long-term development of the industry, this study considers the actual situation in China, and assumes that the simulation time is 10 years, or 120 months, and that the start time is January, 2016, that is, the simulation period is from 2016 to 2025.

The data resources are the China Statistical Yearbook, Chinese Energy Statistics Yearbook, China Environmental Statistics Yearbook, China Technology Statistical Yearbook, and survey data from the China Electricity Council (CES). The initial variables in this model are mainly estimated in the following ways:

(1) Direct determination. Some variable values can be directly obtained from the statistical yearbook or the CES survey data of the Beijing-Tianjin-Hebei region, such as GDP, energy fixed assets, and total quota.

(2) Linear regression method. When assigning some economic auxiliary variables, there is no direct data source in reality, and it is necessary to fit these economic auxiliary variables based on historical data and quantitative regression analysis, such as GDP growth, industrial profits, and environmental governance costs.

(3) Average value method. For some variables that are not significant with time, the average value is taken as the constant value according to the principle of simplifying the model as much as possible, such as the treatment ratio of carbon emission, carbon emissions per unit of energy consumption, supply capacity of energy resources per unit of fixed assets, and the life cycle of industrial fixed assets.

(4) Logical inference. In the process of economic model operation, the initial values of some economic variables cannot meet the needs of the model under the conditions of the above assignment methods. For these economic variables, the initial values are confirmed by repeatedly running through the models according to the statistical data, such as reduction rate of total quota, proportion of free quota, and CT price.

(5) Table function. For some variables that change over time, their values are determined by table functions in Vensim, such as rate of fixed assets investment, proportion of energy investment, and the impact of GDP on energy intensity. The values of each parameter are shown in Table 3. 
Table 3. The values of each parameter.

\begin{tabular}{|c|c|c|c|c|}
\hline Parameter & Value & Unit & Method of Calculation & Data Sources \\
\hline GDP & $74,612.6$ & $10^{8}$ Yuan & Direct determination & [26] \\
\hline Energy fixed assets & $16,273.3$ & $10^{8}$ Yuan & Direct determination & [26] \\
\hline Total quota & 53,417 & $10^{4}$ Tons & Direct determination & survey data from CES \\
\hline Energy intensity & 0.726 & - & Direct determination & {$[32]$} \\
\hline Treatment ratio of carbon emission & $33.6 \%$ & - & Average value & [32] \\
\hline Carbon emissions per unit of energy consumption & 3.89 & Ton/Ton of standard coal & Average value & {$[32,33]$} \\
\hline Supply capacity of energy resources per unit of fixed assets & 54,716 & Ton of standard coal $/ 10^{4}$ Yuan & Average value & {$[31,32]$} \\
\hline Life cycle of industrial fixed assets & 20 & Year & Average value & survey data from CES \\
\hline Reduction rate of total quota & 0.01 & - & Logical inference & {$[22]$} \\
\hline CT price & 40 & Yuan/Ton & Logical inference & [22] \\
\hline GDP growth & (1) of Appendix B & - & Metering method & [26] \\
\hline Industrial profits & (2) of Appendix B & $10^{8}$ Yuan & Metering method & {$[26,32]$} \\
\hline Environmental governance costs & (3) of Appendix B & $10^{8}$ Yuan & Metering method & {$[32,33]$} \\
\hline Rate of fixed assets investment & (4) of Appendix B & - & Table function & {$[21,26]$} \\
\hline Proportion of energy investment & (5) of Appendix B & - & Table function & [32] and survey data from CES \\
\hline The impact of GDP on energy intensity & (6) of Appendix B & - & Table function & {$[26,32]$ and survey data from CES } \\
\hline
\end{tabular}


Here, we need to explain the numbers in the appendix so that the reader can understand the system better. The economic parameter values are determined as follows for some of the formulas of Appendix A, such as (3), (6), (8), (18), (22), (24), and (26). We first use the data of CES to estimate the value and magnitude of each economic parameter according to the relationships among GDP, energy consumption, and $\mathrm{CO}_{2}$ emissions of the Beijing-Tianjin-Hebei region. Then we repeatedly test the model and adjust the parameters' values, so that the SD model can eventually reach a circulatory system, which is stable, sustainable, and consistent with the development trend of the Beijing-Tianjin-Hebei region's 3E system, thereby determining the economic parameters' values. The Formulas (1), (2), and (3) of Appendix B are calculated by linear regression method according to Refs. $[26,32,33]$, and the $\mathrm{R}^{2}$ of these three formulas are $0.976,0.988$, and 0.967 , respectively. Formulas (4), (5), and (6) of Appendix B are calculated according to Refs. [21,26,32] and survey data from CES. The values of these three parameters can only estimate the range of variation and trend of change, and they are not linear growth or decrease. Therefore, we use the table function to determine the value of nonlinear change per year according to their respective range of change and trend.

\subsection{Simulation Results}

In this section, we use real data to simulate the development of the $3 \mathrm{E}$ system under the CT mechanism of the Beijing-Tianjin-Hebei region. In order to facilitate analysis, we simulate the following two scenarios:

Scenario A: Do not implement CT mechanism, that is, total quota, free quota, and CT price are 0 , and other data are unchanged.

Scenario B: Consider CT implementation, and all of data reference Table 3.

The simulation results of GDP, energy consumption, $\mathrm{CO}_{2}$ emissions, and energy gap are shown in Figure 4. In the absence of CT mechanism (Scenario A), the productions of enterprises do not have to consider carbon emissions restrictions without any regulation. With the growth of investment in fixed assets and energy investment year by year, on the one hand, the annual increase in GDP growth making GDP of the Beijing-Tianjin-Hebei region rapidly increases, so that industrial profits and energy consumption increase, and $\mathrm{CO}_{2}$ emissions increase year by year. On the other hand, the continuous increase of energy fixed assets makes the energy supply increase continuously, and the energy gap keeps dropping, thus the effect of energy conservation policy gradually decreases. Due to the annual increase of the impact of GDP on energy intensity, the energy intensity of the Beijing-Tianjin-Hebei region gradually increases because the effect of energy conservation saving is weaker than that of GDP on energy intensity according to Formulas (5) and (6). Coupled with the rapid growth of GDP, energy consumption and $\mathrm{CO}_{2}$ emissions also rapidly grow. By 2019, the energy gap drops to 5 million tons of standard coal, and GDP, energy consumption, and $\mathrm{CO}_{2}$ emissions will reach 8935.1 billion yuan, 699.92 million tons of standard coal, and 1120.37 million tons, respectively. However, with the rapid growth of $\mathrm{CO}_{2}$ emissions, the government gradually increases the treatment investment for carbon emissions, making the environmental governance costs increase. GDP growth is negatively affected, and GDP still grows year by year but the rate of growth is slow. Similarly, the energy supply is negatively affected and its growth slowed down. However, due to the rigid demand of human production and life, energy consumption continues to grow in the short term, which makes the energy gap begin to gradually increase. Although the effect of energy conservation policy becomes large due to the impact of the energy gap, it is always weaker than the impact of GDP on energy intensity, thus, the energy intensity increases, resulting in a further increase of energy consumption, so that the energy gap and $\mathrm{CO}_{2}$ emissions grow faster and faster. GDP, energy consumption, and $\mathrm{CO}_{2}$ emissions of the Beijing-Tianjin-Hebei region will reach 12,038.3 billion yuan, 1256.95 million tons of standard coal, and 1926.82 million tons in 2025, respectively, and the energy gap will reach 1.02 billion tons of standard coal. 


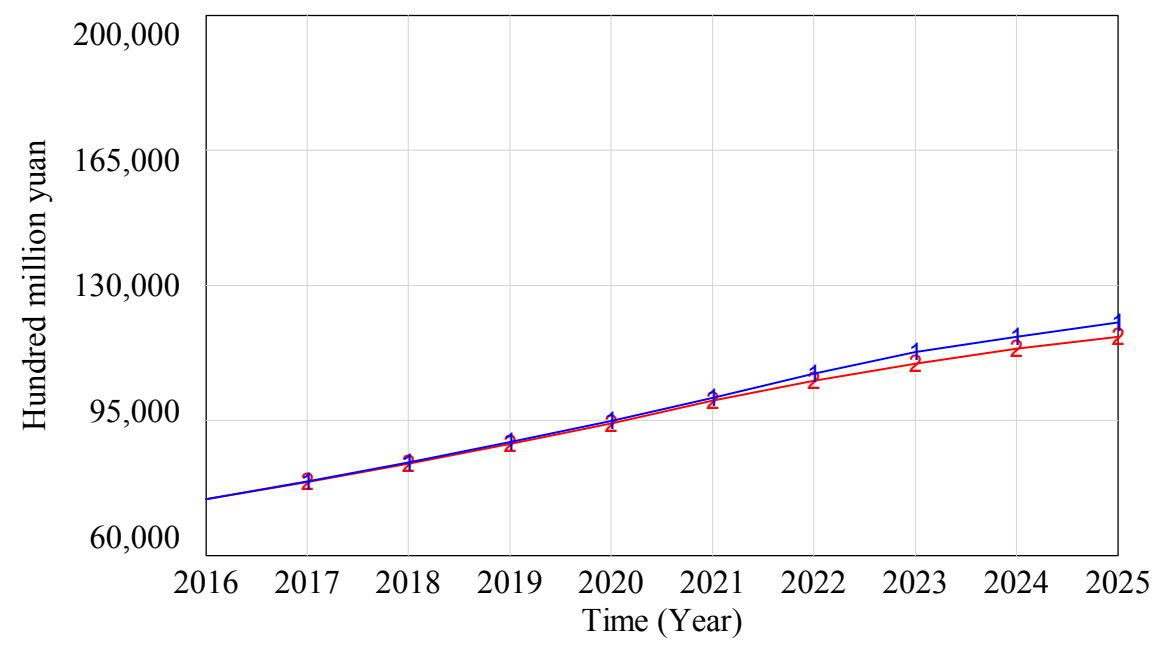

GDP : Scenario A $\begin{array}{lllllll}1 & 1\end{array} \quad$ GDP : Scenario B 2

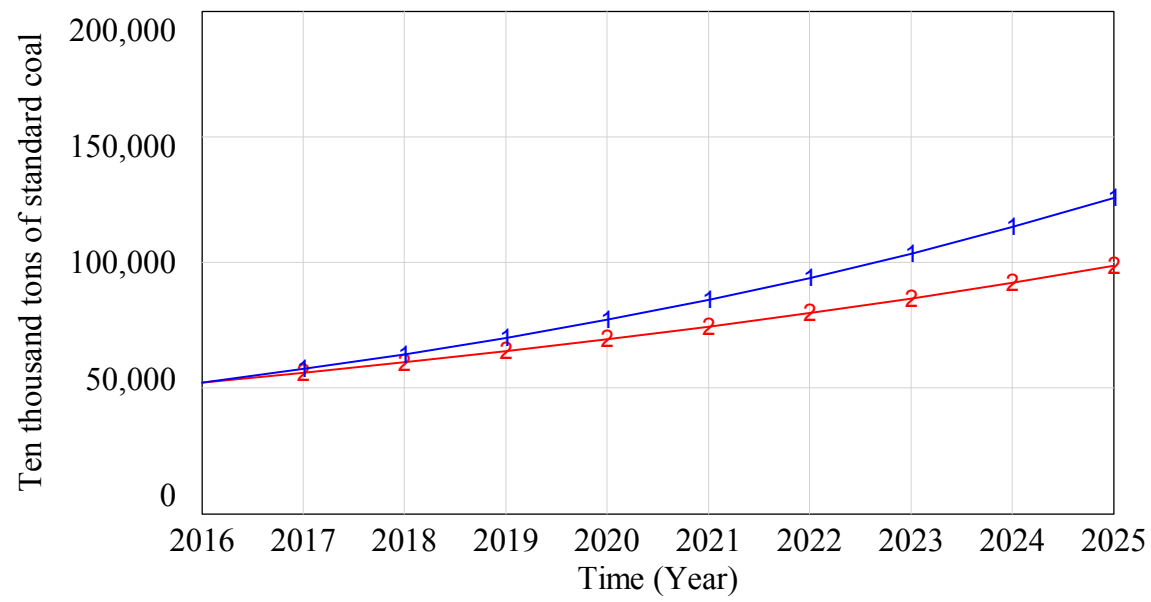

$\begin{array}{lllllllllll}\text { Energy consumption : Scenario A } & 1 & 1 & 1 & 1 & 1 & 1 & 1 & 1 \\ \text { Energy consumption : Scenario B } & 2 & 2 & 2 & 2 & 2 & 2 & 2 & 2\end{array}$

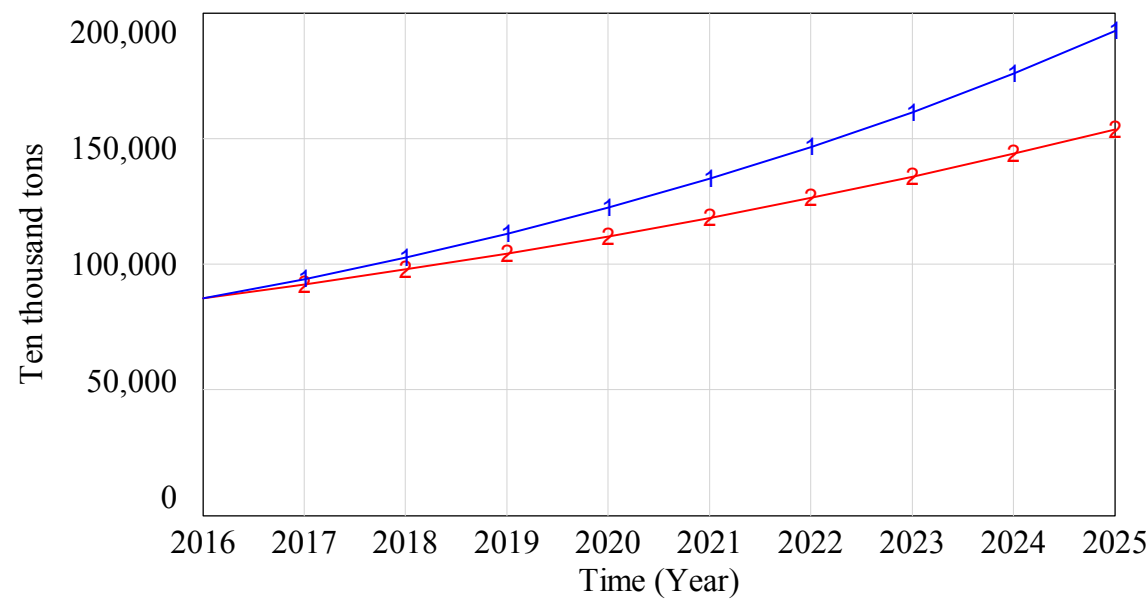

$\mathrm{CO} 2$ emissions : Scenario A 1

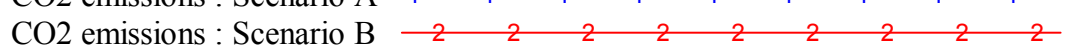

Figure 4. Cont. 


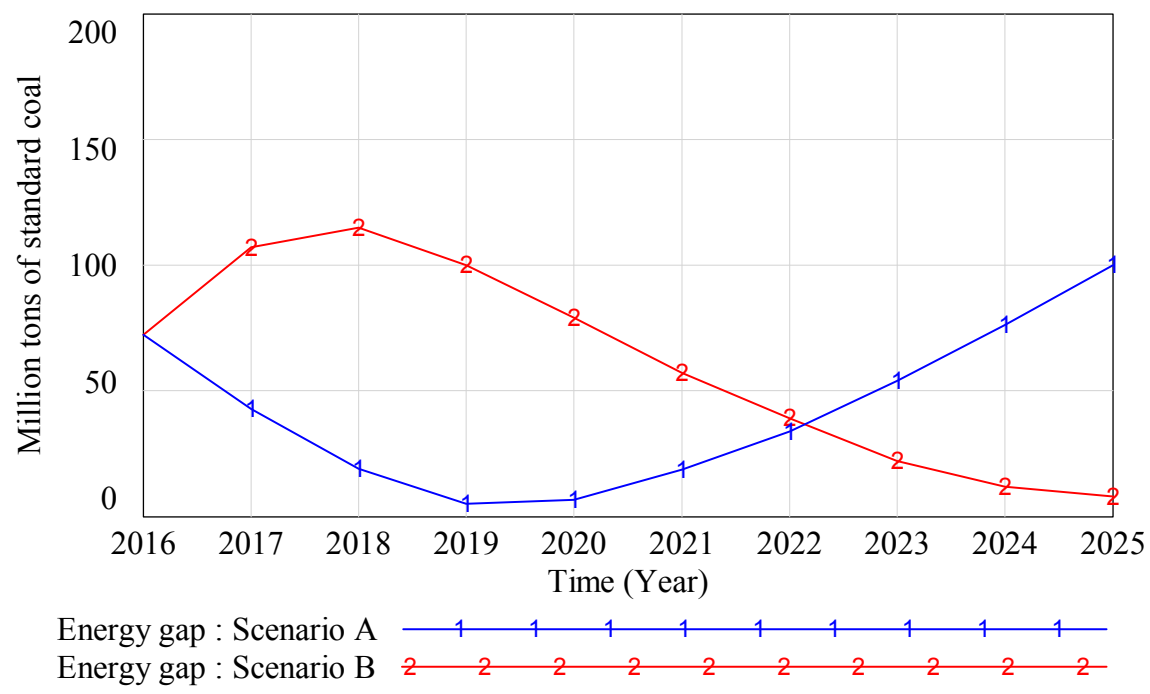

Figure 4. The simulation results of GDP, energy consumption, $\mathrm{CO}_{2}$ emissions, and energy gap. Source: Simulation results from Vensim.

In the context of $\mathrm{CT}$ implementation (Scenario B), the enterprises will pay high carbon emission costs to purchase $\mathrm{CT}$ or pay the fine, making industrial profits decline, which has a negative impact on GDP growth. Thus, the growth rate of GDP is lower than that in Scenario A. The reduction in GDP reduces energy investment, thus reducing energy supply, due to the rigid demand of energy consumption, the energy gap abruptly expands in the short term, and reaches a maximum value of 1.15 billion tons of standard coal in 2018. However, with the implementation of the CT policy and the abrupt expansion of the energy gap, the government increases the effect of energy conservation saving, which is stronger than the impact of GDP on energy intensity, resulting in the reduction of energy intensity. Compared with Scenario A, although the energy consumption continues to grow, the decline of energy intensity and GDP leads to a significant drop in energy consumption, thereby reducing $\mathrm{CO}_{2}$ emissions, and the energy gap begins to decrease after 2018. In addition, we find that the energy gap gradually tends to 0 . This is because carbon emissions are gradually controlled with the implementation of the $\mathrm{CT}$ mechanism. The decline of $\mathrm{CO}_{2}$ emissions and GDP becomes more and more stable, and the CT market gradually balances, which ultimately leads to the balance of the whole 3E system. GDP, energy consumption, and $\mathrm{CO}_{2}$ emissions of the Beijing-Tianjin-Hebei region will reach 11,668.3 billion yuan, 987.16 million tons of standard coal, and 1536.22 million tons in 2025 , respectively.

We find from the above results that the unmanaged carbon emissions of enterprises make energy consumption and $\mathrm{CO}_{2}$ emissions rapidly grow without any regulation and control, while increasing the investment burden of the government's environmental governance, eventually leading to slow GDP growth, and a 3E system that cannot be balanced. In contrast, after the implementation of the CT mechanism, the enterprises have to pay the carbon emission costs, and the industrial profits decline. However, the energy consumption and $\mathrm{CO}_{2}$ emissions are greatly reduced, and the energy gap gradually declines, and the $3 \mathrm{E}$ system reaches a balance. In addition, we can see from Figure 4 that the negative impact of CT implementation on GDP is significantly lower than its positive impact on reducing carbon emissions and energy consumption. Thus, the CT mechanism is conducive to the sustainable development of the Beijing-Tianjin-Hebei region's 3E system, and the positive impact of the CT mechanism on the 3E system becomes more and more important as time goes on. 


\section{Discussion}

Some of the exogenous variables in the model can be controlled by the government, such as reduction rate of total quota, proportion of free quota, and CT price. The government adjusts the value of these variables by adjusting the policy, thus acting on the CT market, and ultimately affecting the development direction of the $3 \mathrm{E}$ system. The gradual reduction of total quota will become an inevitable trend considering the ultimate goal of carbon emission reduction, and the reduction rate of total quota will gradually increase to achieve the goal of carbon emission reduction. Similarly, in order to increase the scale of market transactions, the proportion of free quotas will also gradually decrease. The CT price will also affect the market transactions. Thus, in this section, we 1 discuss the impact of these three variables on the 3E system's development of the Beijing-Tianjin-Hebei region.

\subsection{Reduction Rate of Total Quota}

We set $0.02,0.03$, and 0.04 of reduction rate of total quota as Scenarios C, D, and E, respectively, and the simulation results are shown in Figure 5. The gradual increase of the quota reduction rate means that the total amount of quota will gradually decrease. The simulation results show that the reduction of the total quota contributes to carbon emission reduction but at the same time it will inhibit GDP growth. This shows that the less the total quota, the fewer carbon emission credits the enterprise can obtain in the carbon market, and the higher the carbon emission costs, which are an important part of production costs, for enterprises to meet their production needs. According to the principle of cost minimization, an enterprise may reduce its production capacity to a certain extent so as to reduce its carbon emission costs. The corresponding decrease in production capacity will have a certain negative effect on GDP.

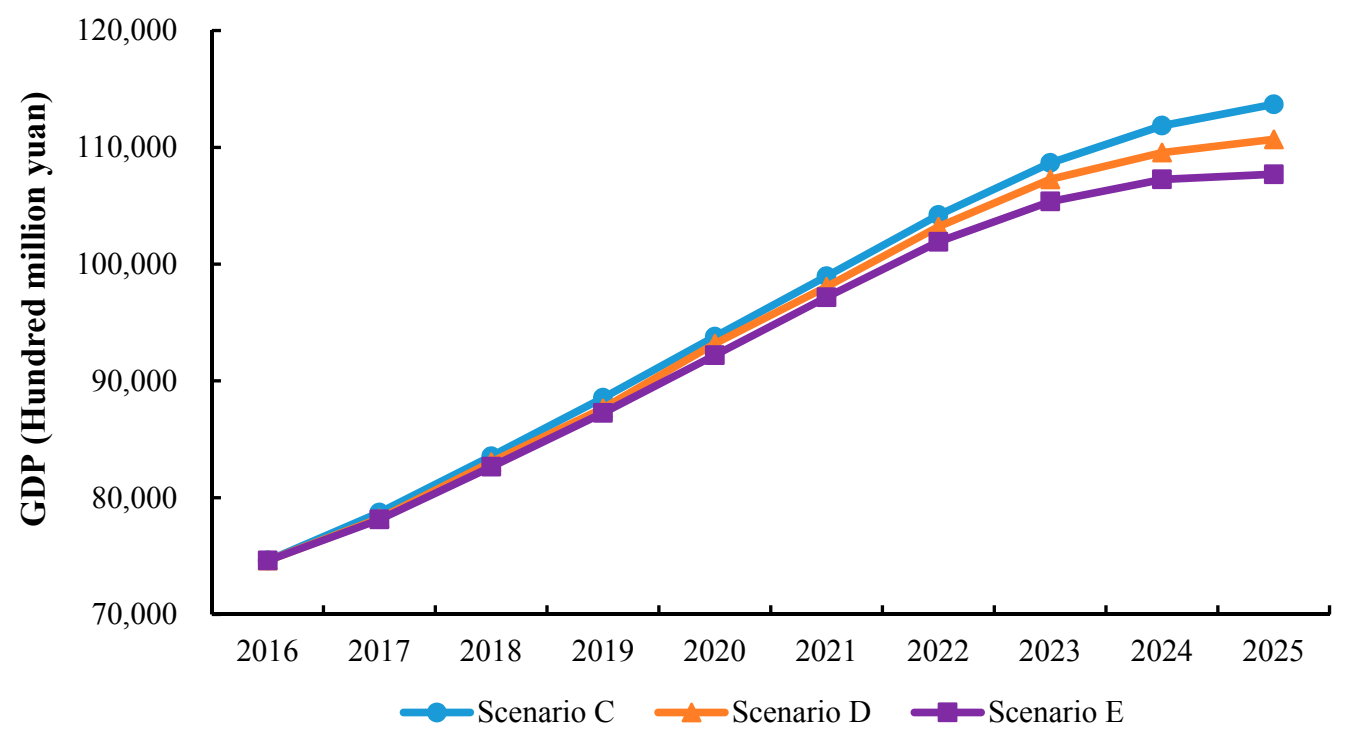

(a)

Figure 5. Cont. 


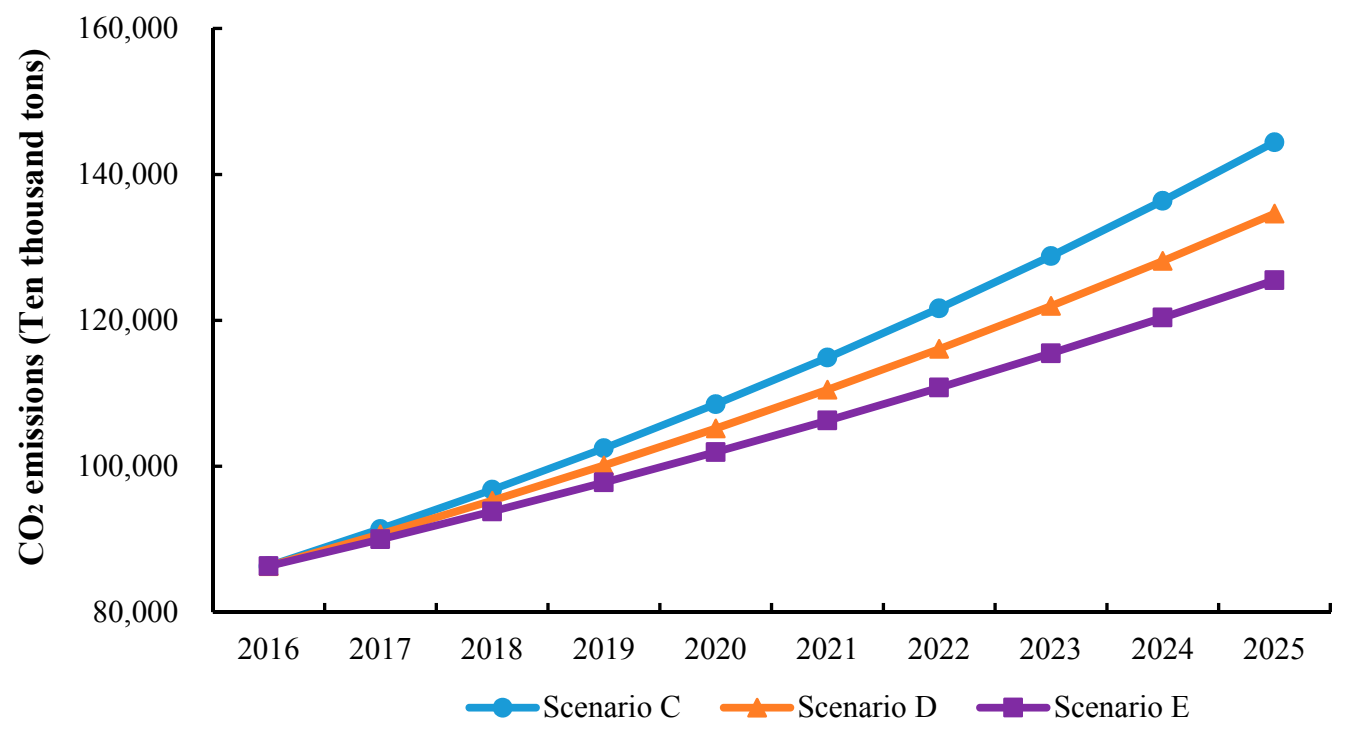

(b)

Figure 5. The simulation results of reduction rate of total quota. Source: Simulation results from Vensim and arrangement from authors. (a) GDP's results under various reduction rates of total quota; (b) $\mathrm{CO}_{2}$ emissions' results under various reduction rates of total quota.

\subsection{Proportion of Free Quota}

We set $0.7,0.8$, and 0.9 of proportion of free quota as Scenarios F, G, and H, respectively, and the simulation results are shown in Figure 6. The simulation results show that the increase of free quota makes the carbon emission costs smaller, which weakens the emission reduction effect of the carbon trading mechanism, so that the carbon emissions and GDP of the Beijing-Tianjin-Hebei region increase.

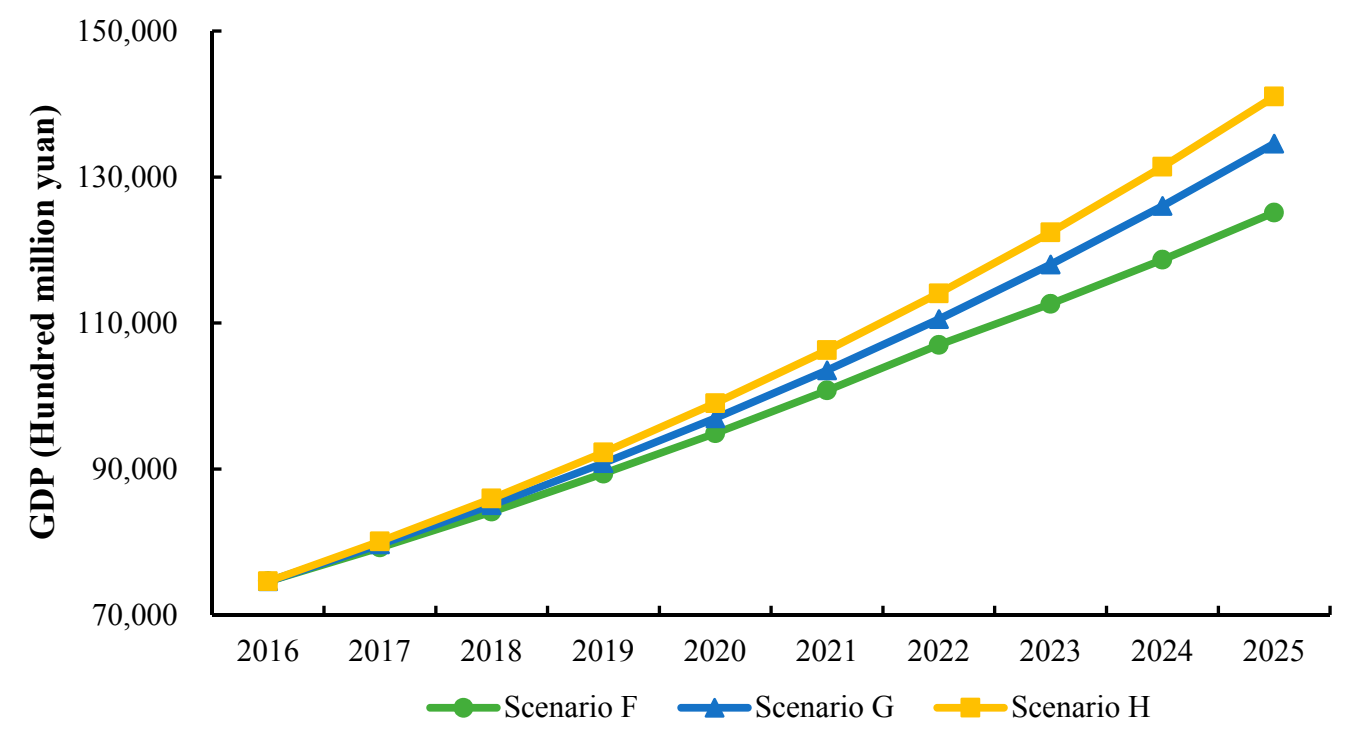

(a)

Figure 6. Cont. 


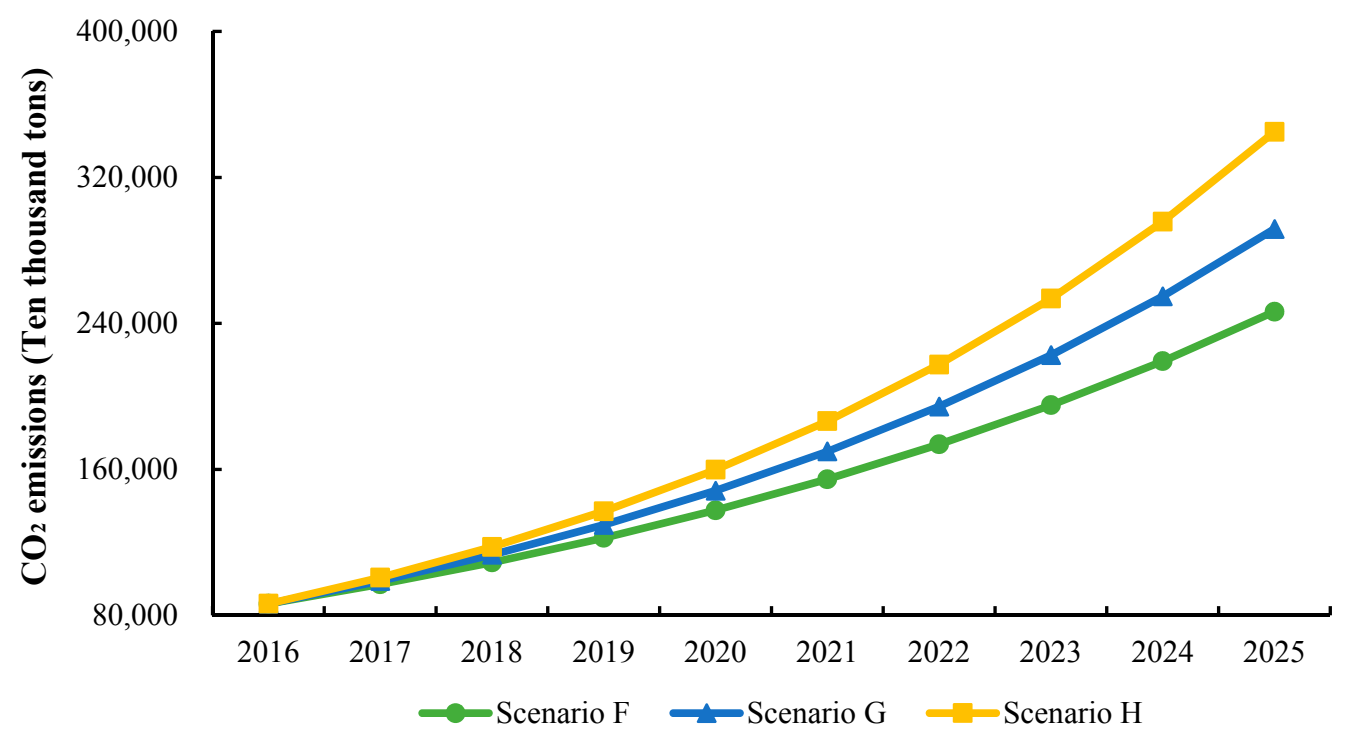

(b)

Figure 6. The simulation results of the proportion of free quota. Source: Simulation results from Vensim and arrangement from authors. (a) GDP's results under various proportions of free quota; (b) $\mathrm{CO}_{2}$ emissions' results under various proportions of free quota.

\subsection{CT Price}

We set 50, 60, and 70 of CT price as Scenarios I, J, and K, respectively, and the simulation results are shown in Figure 7. The simulation results show that the carbon emissions and GDP gradually decrease with the increase of CT price. This shows that the $\mathrm{CT}$ price will increase the enterprises' carbon emission costs, which will lead to a greater restriction on $\mathrm{CO}_{2}$ emissions and a negative impact on GDP.

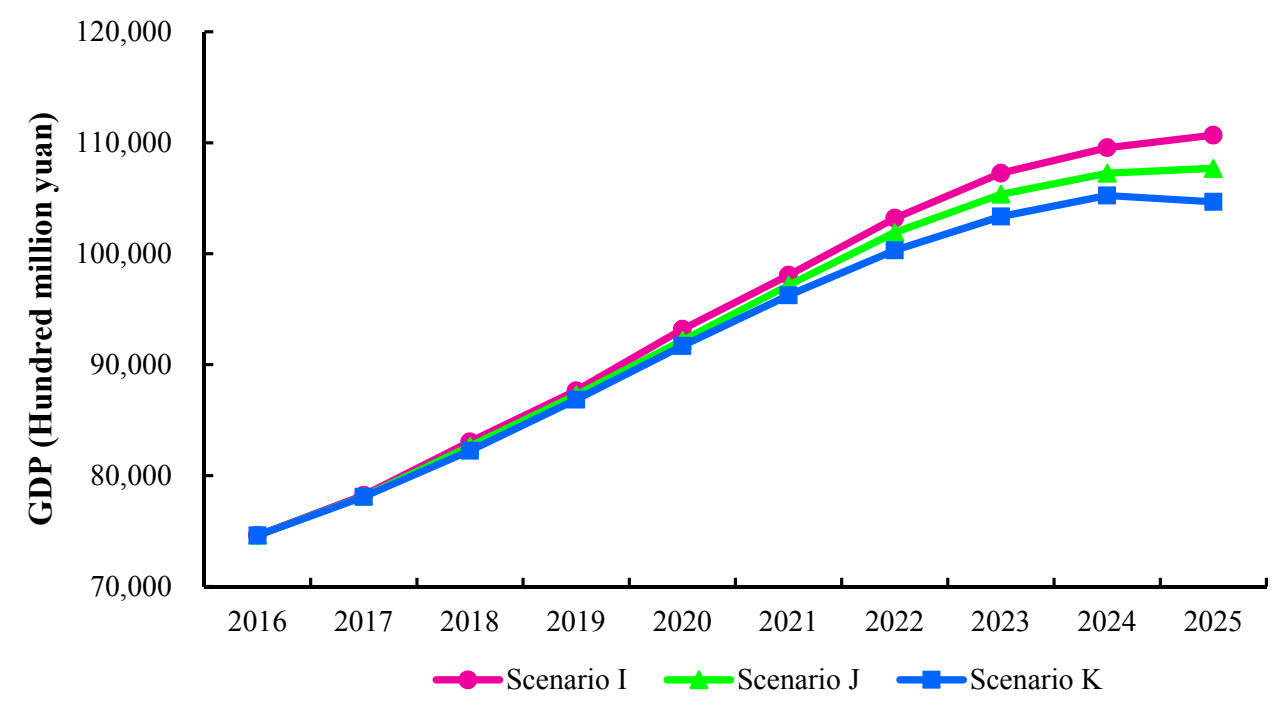

(a)

Figure 7. Cont. 


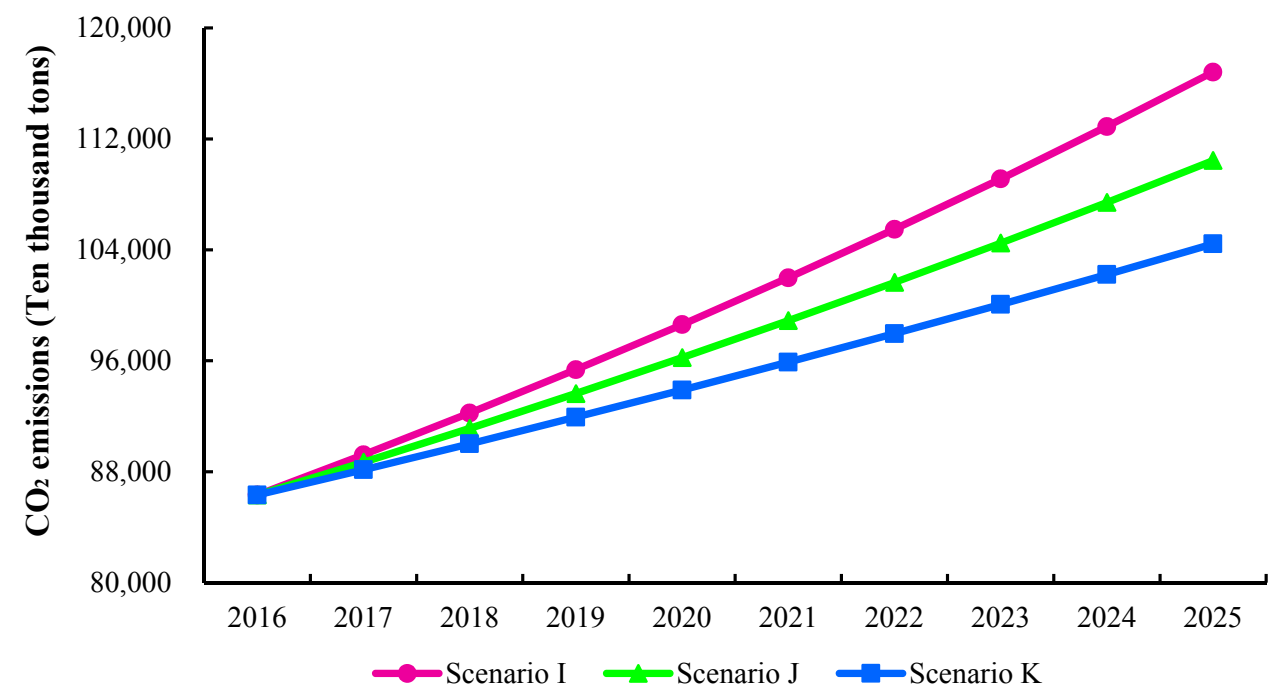

(b)

Figure 7. The simulation results of CT price. Source: Simulation results from Vensim and arrangement from authors. (a) GDP's results under various $\mathrm{CT}$ prices; (b) $\mathrm{CO}_{2}$ emissions' results under various CT prices.

\section{Conclusions}

The coordinated development of 3E in the Beijing-Tianjin-Hebei region has been paid much attention by the Chinese government. The $3 \mathrm{E}$ system under the CT mechanism of the Beijing-TianjinHebei region is a typical complex system, which is influenced by many factors. Therefore, this paper constructs a 3E model based on SD, and studies the internal operation mechanism of CT system and its impact on $3 \mathrm{E}$ by combing the relationship between $\mathrm{CT}$ policy, $\mathrm{CO}_{2}$ emissions, energy consumption, and GDP. On the basis of qualitative analysis, this paper combines quantitative analysis and policy optimization simulation to provide theoretical guidance and countermeasures for the realization of carbon emission reduction targets in the Beijing-Tianjin-Hebei region and the development of a low-carbon economy.

According to the simulation results of the model, we can draw the following conclusions: (1) The SD model established in this paper can well describe and simulate the trend of the 3E system's sustainable development under the CT mechanism of the Beijing-Tianjin-Hebei region, which can provide references for scholars to study the impact of CT policy on the 3E system in other regions; (2) The long-term development of the Beijing-Tianjin-Hebei region's 3E system is not sustainable under the current situation. However, the implementation of CT can effectively reduce the energy consumption growth and carbon emissions, and the negative impact of CT implementation on GDP is significantly lower than its positive impact on reducing carbon emissions and energy consumption. Thus, the CT mechanism is conducive to the sustainable development of the Beijing-Tianjin-Hebei region's 3E system; (3) Reducing the total amount of quota, reducing free quota, and increasing the CT price can effectively promote carbon emission reduction, thus promoting the sustainable development of the $3 \mathrm{E}$ system.

This paper notes some limitations that are still to be improved upon. The paper only considers the impact of carbon emission costs on the production costs and enterprises' profits, but does not involve the whereabouts. On the one hand, the government can return carbon revenue as subsidies to enterprises, which will reduce the negative impact of CT on the economy. On the other hand, the government can invest carbon revenue into the development and utilization of clean energy to promote the improvement of CT policy for the environment. These problems will be the main direction of our continuous improvement of the simulation model of the CT mechanism in the future. 
Acknowledgments: This paper is supported by the National Natural Science Foundation of China (No. 71273088), the Beijing Municipal Social Science Foundation (No. 16JDYJB031), 2017 Special Project of Cultivation and Development of Innovation Base (No. Z171100002217024), and Science and Technology Project funding by State Grid Corporation of China (No. 27KJ010501C1016320140000).

Author Contributions: Xingang Zhao was mainly responsible for the writing of the full text. Yuzhuo Zhang conceived and designed the experiments, and wrote the first half of the paper. Ji Liang wrote the second half of the paper. Yanbin Li built the models of the paper. Rongda Jia made the final revision. Ling Wang provided financial support.

Conflicts of Interest: The authors declare no conflicts of interest.

\section{Appendix A}

All the formulas of SD are as follows:

(1) Carbon emission costs $=\mathrm{CT}$ amounts $\times$ CT price + Fine amounts $\times$ Fine price

(2) Carbon emissions per unit of energy consumption $=3.89$

(3) $\mathrm{CO}_{2}$ emissions $=$ Carbon emissions per unit of energy consumption $\times$ Energy consumption-Treatment investment of carbon emission $\times 2 \times 10^{-2}$

(4) CT amounts $=$ Total quota - Free quota amount

(5) $\mathrm{CT}$ price $=40$

(6) Decrease of energy intensity $=$ Effect of energy conservation policy - GDP $\times$ The impact of GDP on energy intensity $\times 1.2 \times 10^{-5}$

(7) Depreciation of energy fixed assets = Energy fixed assets $/$ Life cycle of industrial fixed assets

(8) Effect of energy conservation policy $=$ Intensity of energy conservation policies $\times 1.1$

(9) Energy consumption $=$ Energy intensity $\times$ GDP

(10) Energy fixed assets = INTEG (Increment of energy fixed asset - Depreciation of energy fixed assets, 16,273.3)

(11) Energy gap = Energy consumption - Energy supply

(12) Energy intensity = INTEG (Decrease of energy intensity, 0.726)

(13) Energy investment $=$ GDP $\times$ Proportion of energy investment

(14) Energy supply $=$ Energy fixed assets $\times$ Supply capacity of energy resources per unit of fixed assets

(15) Environmental governance costs $=0.0258 \times \mathrm{CO}_{2}$ emissions -782.15

(16) Environmental investment $=$ GDP $\times$ Investment proportion of environmental protection

(17) Fine amounts $=\mathrm{CO}_{2}$ emissions $-\mathrm{CT}$ amounts - Free quota amount

(18) Fine price $=0.2 \times \mathrm{CT}$ price

(19) Free quota amount $=\mathrm{CO}_{2}$ emissions $\times$ Proportion of free quota

(20) GDP = INTEG (GDP growth, 74612.6)

(21) GDP growth $=1912.12+4.116 \times$ Industrial profits $+0.828 \times$ Investment in fixed assets $-8.585 \times$ Environmental governance costs

(22) Increment of energy fixed asset $=$ Energy investment $\times 1.6 \times 10^{-5}$

(23) Industrial profits $=-5 \times 10^{-11} \times \mathrm{GDP}^{3}+5 \times 10^{-6} \times \mathrm{GDP}^{2}-0.0336 \times \mathrm{GDP}+274.77-$ Carbon emission costs

(24) Intensity of energy conservation policies = Energy gap $\times 3 \times 10^{-4}$

(25) Investment in fixed assets $=$ GDP $\times$ Rate of fixed assets investment

(26) Investment proportion of environmental protection $=\mathrm{CO}_{2}$ emissions $\times 9 \times 10^{-3}$

(27) Life cycle of industrial fixed assets $=240$

(28) Proportion of energy investment = WITH LOOKUP (Time, $([(2016,0.25)-(2025,0.43)],(2016$, $0.25),(2017,0.27),(2018,0.28),(2019,0.3),(2020,0.31),(2021,0.33),(2022,0.36),(2023,0.38),(2024$, $0.41),(2025,0.43)))$

(29) Proportion of free quota $=0.6$ 
(30) Rate of fixed assets investment $=$ WITH LOOKUP $($ Time, $([(2016,0.65)-(2025,0.75)],(2016$, $0.658),(2017,0.664),(2018,0.673),(2019,0.686),(2020,0.695),(2021,0.712),(2022,0.724),(2023$, $0.733),(2024,0.736),(2025,0.741))$

(31) Reduction rate of total quota $=0.01$

(32) Supply capacity of energy resources per unit of fixed assets $=54,716$

(33) The impact of GDP on energy intensity = WITH LOOKUP (Time, $([(2016,1)-(2025,2)],(2016$, 1),(2017, 1.1),(2018, 1.2),(2019, 1.4),(2020, 1.5),(2021, 1.6),(2022, 1.7),(2023, 1.8),(2024, 1.9),(2025, 2)))

(34) Total quota = INTEG (Total quota reduction, 53,417)

(35) Total quota reduction $=$ Total quota $\times$ Reduction rate of total quota

(36) Treatment investment of carbon emission $=$ Environmental investment $\times$ Treatment ratio of carbon emission

(37) Treatment ratio of carbon emission $=0.336$

\section{Appendix B}

(1) GDP growth $=1912.12+4.116 \times$ Industrial profits $+0.828 \times$ Investment in fixed assets $-8.585 \times$ Environmental governance costs

(2) Industrial profits $=-5 \times 10^{-11} \times \mathrm{GDP}^{3}+5 \times 10^{-6} \times \mathrm{GDP}^{2}-0.0336 \times \mathrm{GDP}+274.77-$ Carbon emission costs

(3) Environmental governance costs $=0.0258 \times \mathrm{CO}_{2}$ emissions -782.15

(4) $\quad([(2016,0.65)-(2025,0.75)],(2016,0.658),(2017,0.664),(2018,0.673),(2019,0.686),(2020,0.695),(2021$, $0.712),(2022,0.724),(2023,0.733),(2024,0.736),(2025,0.741))$

(5) $\quad([(2016,0.25)-(2025,0.43)],(2016,0.25),(2017,0.27),(2018,0.28),(2019,0.30),(2020,0.31),(2021$, $0.33),(2022,0.36),(2023,0.38),(2024,0.41),(2025,0.43))$

(6) $([(2016,1)-(2025,2)],(2016,1.0),(2017,1.1),(2018,1.2),(2019,1.4),(2020,1.5),(2021,1.6),(2022$, $1.7),(2023,1.8),(2024,1.9),(2025,2.0))$

\section{References}

1. China Stock Net. The Chinese Government Will Set up a Nationwide CT Market by 2018. 2017. Available online: http:/ / news.cnstock.com/news,bwkx-201711-4156446.htm (accessed on 26 November 2017).

2. Chappin, E.J.L.; Dijkema, G.P.J. On the impact of $\mathrm{CO}_{2}$, emission-trading on power generation emissions. Technol. Forecast. Soc. Chang. 2009, 76, 358-370. [CrossRef]

3. Mo, J.L.; Zhu, L.; Fan, Y. The impact of the EU ETS on the corporate value of European electricity corporations. Energy 2012, 45, 3-11. [CrossRef]

4. Tang, L.; Wu, J.; Yu, L.; Bao, Q. Carbon emissions trading scheme exploration in China: A multi-agent-based model. Energy Policy 2015, 81, 152-169. [CrossRef]

5. Cong, R.G.; Wei, Y.M. Potential impact of carbon emissions trading (CET) on China's power sector: A perspective from different allowance allocation options. Energy 2010, 35, 3921-3931. [CrossRef]

6. Zhao, X.; Jiang, G.; Nie, D.; Chen, H. How to improve the market efficiency of carbon trading: a perspective of China. Renew. Sustain. Energy Rev. 2016, 59, 1229-1245. [CrossRef]

7. Wang, Q.; Wang, S. Study on market efficiency of China's carbon trading market. Soc. Sci. J. 2014, 4, 30-36.

8. Zhao, X.G.; Wu, L.; Li, A. Research on the efficiency of carbon trading market in China. Renew. Sustain. Energy Rev. 2017, 79, 1-8. [CrossRef]

9. Liu, J.P.; Zhang, X.B.; Song, X.H. Regional carbon emission evolution mechanism and its prediction approach driven by carbon trading-A case study of Beijing. J. Clean. Prod. 2017. [CrossRef]

10. Kanamura, T. Role of carbon swap trading and energy prices in price correlations and volatilities between carbon markets. Energy Econ. 2016, 54, 204-212. [CrossRef]

11. Rannou, Y.; Barneto, P. Futures trading with information asymmetry and OTC predominance: Another look at the volume/volatility relations in the European carbon markets. Energy Econ. 2014, 53, 159-174. [CrossRef] 
12. Balietti, A.C. Trader types and volatility of emission allowance prices. Evidence from EU ETS phase I. Energy Policy 2015, 98, 607-620. [CrossRef]

13. Yin, L.; Mei, F. The Short Economic Impact of Carbon Emission Trade System on High Energy-consuming Industries in Hubei Province. J. Sichuan Normal Univ. 2016, 39, 437-443.

14. Zhou, S. Economic and Environmental Impacts of the Shanghai Carbon Emission Trading: Based on CGE Model Analysis. Adv. Clim. Chang. Res. 2015, 11, 144-152.

15. Zhang, X.; Qi, T.Y.; Ou, X.M.; Zhang, X.L. Research on the Energy and Economic Impacts of Multi-region Linked Emissions Trading System. Energy Procedia 2015, 75, 2495-2503.

16. Koljonen, T.; Savolainen, I. Impact of the EU Emissions Trading Directive on the Energy and Steel Industries in Finland. Available online: https:/ / www.sciencedirect.com/science/article/pii/B9780080447049500847 (accessed on 1 January 2018).

17. Schleich, J.; Rogge, K.; Betz, R. Incentives for energy efficiency in the EU Emissions Trading Scheme. Energy Effic. 2009, 2, 37-67. [CrossRef]

18. Kamarzamana, N.A.; Tan, C.W. A comprehensive review of maximum power point tracking algorithms for photovoltaic systems. Renew. Sustain. Energy Rev. 2014, 37, 585-598. [CrossRef]

19. Ming, Z.; Zhang, K.; Dong, J. Overall review of China's wind power industry: Status quo, existing problems and perspective for future development. Renew. Sustain. Energy Rev. 2013, 24, 379-386. [CrossRef]

20. Guo, X.D.; Guo, X.P. China's photovoltaic power development under policy incentives: A system dynamics analysis. Energy 2015, 93, 589-598. [CrossRef]

21. Zuo, Y.; Shi, Y.L.; Zhang, Y.Z. Research on the Sustainable Development of an Economic-Energy-Environment (3E) System Based on System Dynamics (SD): A Case Study of the Beijing-Tianjin-Hebei Region in China. Sustainability 2017, 9, 1727. [CrossRef]

22. Zhang, J.R.; Wang, Z.D.; Tang, L.; Yu, L.A. The Simulation of Carbon Emission Trading System in Beijing-Tianjin-Hebei Region: An Analysis Based on System Dynamics. Chin. J. Manag. Sci. 2016, 24, 1-8.

23. Yuan, C.Q.; Liu, S.F.; Guo, B.H. System dynamics modeling and imitation for Chinese energy-economy system. Chin. J. Manag. Sci. 2011, 19, 717-724. (In Chinese)

24. Beijing Municipal Commission of Development \& Reform. Interim Measures for the Management of Carbon Emissions Trading. 2017. Available online: http:/ / www.bjpc.gov.cn/ (accessed on 9 December 2014).

25. Sgouridis, S.; Csala, D. A Framework for Defining Sustainable Energy Transitions: Principles, Dynamics, and Implications. Sustainability 2014, 6, 2601-2622. [CrossRef]

26. State Statistical Bureau. China Statistical Yearbook 2016; China Statistics Press: Beijing, China, 2017.

27. Han, R.; Tang, B.J.; Fan, J.L.; Liu, L.C.; Wei, Y.M. Integrated weighting approach to carbon emission quotas: an application case of Beijing-Tianjin-Hebei region. J. Clean. Prod. 2016, 131, 448-459. [CrossRef]

28. Zhu, L.; Gan, Q.; Liu, Y.; Yan, Z. The impact of foreign direct investment on $\mathrm{SO}_{2}$ emissions in the Beijing-Tianjin-Hebei region: A spatial econometric analysis. J. Clean. Prod. 2017, 166, 189-196. [CrossRef]

29. Zhao, H.; Zhang, Q.; Huo, H.; Lin, J.; Liu, Z.; Wang, H.; Guan, D.; He, K. Environment-economy trade off for Beijing-Tianjin-Hebei's exports. Appl. Energy 2016, 184, 926-935. [CrossRef]

30. Zhang, Z.; Wang, W.; Cheng, M.; Liu, S.; Xu, J.; He, Y.; Meng, F. The contribution of residential coal combustion to PM 2.5, pollution over China's Beijing-Tianjin-Hebei region in winter. Atmos. Environ. 2017, 159, 147-161. [CrossRef]

31. Zhang, Y.Z.; Zhao, X.G.; Ren, L.Z.; Liang, J.; Liu, P.K. The development of China's biomass power industry under feed-in tariff and renewable portfolio standard: A system dynamics analysis. Energy 2017, 139, 947-961.

32. State Statistical Bureau. Chinese Energy Statistics Yearbook 2016; China Statistics Press: Beijing, China, 2017; pp. 116-221.

33. State Statistical Bureau. Chinese Environmental Statistics Yearbook 2016; China Statistics Press: Beijing, China, 2017; pp. 56-92.

(C) 2018 by the authors. Licensee MDPI, Basel, Switzerland. This article is an open access article distributed under the terms and conditions of the Creative Commons Attribution (CC BY) license (http:/ / creativecommons.org/licenses/by/4.0/). 